\title{
Placenta percreta with silent rupture of the uterus
}

Women's Assistance Center, College of Medical Sciences - CMS. Department of Obstetrics and Gynecology. State University of Campinas - Campinas, Brazil

\begin{abstract}
We report a case of placenta percreta diagnosed by ultrasound and color doppler image at the fourteenth week of gestation. Initial approach was a trial of IM methotrexate followed by total hysterectomy, during which was observed a rupture of the uterus with the adherence of the placenta to the posterior region of the bladder. We also present a literature review on the incidence of placenta percreta, etiology, diagnosis, treatment, and complications.
\end{abstract}

UNITERMS: Placenta accreta. Rupture of the uterus.

$\mathrm{P}$ lacenta percreta is a rare condition with high mortality and morbidity rates for the mother and the fetus. Early diagnosis is difficult and there are very few reports of ultrasonographic diagnosis in the second trimester.

We report a case of placenta percreta diagnosed by ultrasonography during the fourteenth week which was treated with a combination of methotrexate and surgery. During surgery, a silent uterine rupture at a previous incision was observed, through which the placenta had passed and adhered to the cystic bladder.

\section{Adress for correspondence:}

Renato Passini Junior

Divisão de Obstetricia/DIG/FCM/CAISM

Rua Alexande Flemming, 101 - Caixa Postal 6030

Campinas/SP - Brasil - CEP 13092-340

\section{CASE REPORT}

C.S.O., mulatto, married, housekeeper, three prior Caesarean sections, one abortion.

On Jan. 1, 1995, this patient presented a history of intermittent vaginal bleeding for one month and a pregnancy diagnosed at another hospital. Upon examination she was in good condition with no heart, pulmonary, or abdominal alterations. Specular examination showed discrete bleeding through the external os of the cervix. Vaginal examination showed an enlarged uterus in relation to that expected for a fourteenth week pregnancy and the external os was impervious. Initial diagnosis was risk of abortion.

Ultrasonographic and doppler flow evaluation showed an anterior marginal placenta previa $20 \mathrm{~mm}$ thick with a uterine invasion reaching the serosa of the bladder, and a 14-15 week-old fetus. Cystoscopy did not show any alterations. 
The patient was released on Jan. 25 (due to social problems) in good condition; she was readmitted on Jan. 31 .

After a literature survey and discussion with the patient, and due to the high risk involved, the proposed treatment was therapeutic abortion with a single dose of methotrexate to reduce placenta vascularization.

She received $50 \mathrm{mg} / \mathrm{m}^{2}(62.5$ $\mathrm{mg}$ ) of methotrexate and $120 \mathrm{mg}$ of endovenous folinic acid on Feb. 2 ; echographic studies done after administration showed no clinical changes after seven days.

The response to treatment was considered inadequate. Surgery was decided upon after further discussion with the patient.

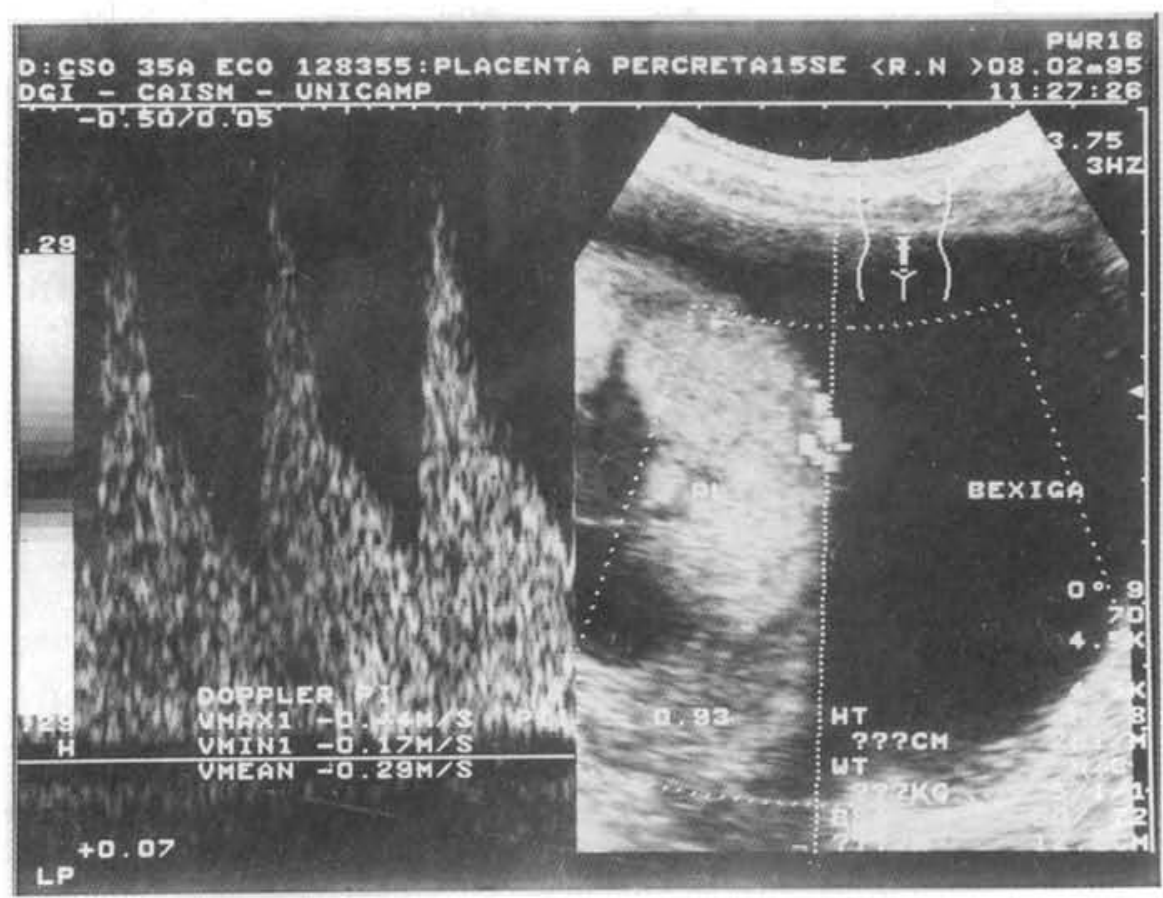

Figure 1 - Ultrasonogram and color doppler showing placentary flow on bladder wall.
On Feb. 14 she underwent a total abdominal extra fascicular hysterectomy. During surgery a silent rupture of the uterus through the scar of a previous Caesarean section was observed. The placenta had gone through it and reached the bladder, adhering to an area of approximately $2 \mathrm{~cm}$, which was not resected, since it presented no bleeding. During and after the operation a $2000 \mathrm{ml}$ hemorrhage occurred, after which she received a transfusion of two units of red blood cells.

The patient left the hospital on Feb. 20 in good condition and without complications.

\section{DISCUSSION}

Placenta percreta is the most serious abnormal adherence to the uterus wall (placenta accreta), and it occurs when there is penetration of the tissue through the myometrium of the uterus and serosa, with the possible involvement of other organs.

The incidence of placenta accreta varies from 1:540 (Thailand) 1.2 to 1:93,000 pregnancies. ${ }^{2}$ The incidence of placenta percreta varies from 1:3333 pregnancies $^{3}$ to $1: 1,400,000$. $^{\prime}$

Etiology is not well defined. It is possibly related to a failure in the decidua basalis which would allow placenta invasion into the myometrium. Several conditions that accompany placenta accreta were observed: placenta previa; ${ }^{1.2}$ a previous Caesarean section; ${ }^{1.2}$ multiple pregnancies; ${ }^{2.4}$ a history of dilation and curettage, $;^{1.2,4}$ and a history of manual extraction of the placenta, which would indicate a previous adherence. ${ }^{1,2,4}$

Clinical diagnosis occurs usually during the third trimester due to excessive bleeding and/or difficulty in placenta extraction. ${ }^{2.5 .6}$ Although it is a rare and difficult diagnosis, it is possible to use ultrasonography and doppler flow evaluation. ${ }^{2.36 .7}$ Early diagnosis is important since it allows assessment of the extension of the placenta invasion, discussion about the treatment, and a better preparation of the team at procedure (i.e. hemotherapeutic support). ${ }^{2.3 .7}$ Therefore, a thorough ultrasonographic examination is suggested for patients with risk factors for placenta accreta. ${ }^{2,6.7}$

Since diagnosis usually occurs during delivery, measures should be taken at that time (which usually means hysterectomy). ${ }^{1,2.4}$ Recently, there has been a tendency towards a more conservative treatment, ${ }^{2.3}$ due to early diagnosis, which permits the prediction of possible complications and assessment of the benefits of each type of treatment. ${ }^{2.3 .7}$ Conservative treatment still presents several complications ${ }^{1,3.6,7}$ and high morbidity and mortality rates. ${ }^{1.26}$ Therefore, it requires precise indications and a strict follow-up.

Methotrexate was initially used as chemotherapy for treatment of gestational trophoblastic disease, since it diminishes trophoblastic activity, placenta vascularization 

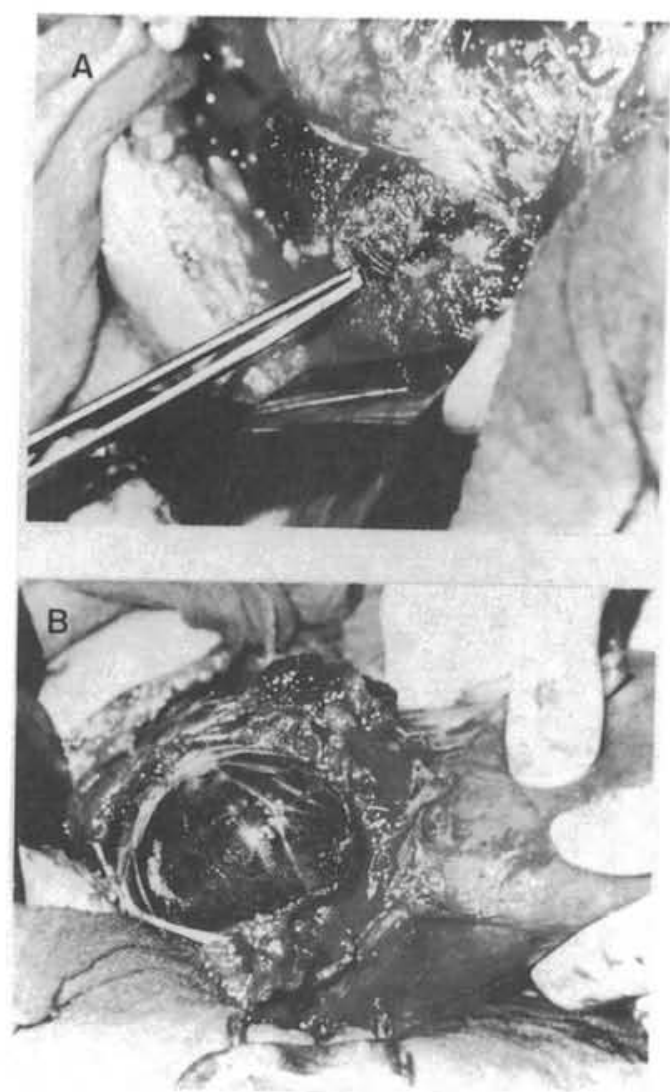

Figure 2 - Spontaneous rupture of the uterus observed after section of visceral peritoneum. 2A. Uterine rupture as seen on anterior hysterorrhaphy. 2B. Placenta and ovular sac passing through rupture of the uterus.
The principal complication reported in placenta accreta is hemorrhage, which may occur before, during, or after birth. ${ }^{13.4}$ It may also cause hypovolemic shock and death, ${ }^{1.4 .7}$ besides increasing the need for blood transfusions $\left[\mathrm{READ}^{4}\right.$ shows a follow-up of 22 patients, necessary transfusions $=0-39$ units $/$ patient (median=7.9 units)] Other complications may be: coagulation problems, ${ }^{4}$ rupture of the uterus,,$^{4.7}$ anemia, ${ }^{4}$ infection and ${ }^{4}$ endometriosis. ${ }^{4}$ Maternal mortality rates are variable, but may surpass 6.5 percent in cases of placenta percreta with invasion of the bladder, or the large or Bowel's ligament. ${ }^{\text {? }}$

\section{CONCLUSION}

Placenta percreta is a rare disease with a difficult initial diagnosis. We suggest that ultrasonography be carried out carefully in high risk patients. Early diagnosis enables a thorough discussion of the procedures, and/or assessment of the risks and benefits in each case.

A conservative approach to chemotherapy, such as methotrexate, is a relatively new and has not been tested. Its effectiveness has not yet been proved with placenta percreta; however, its results with ectopic pregnancies show that it may be a viable procedure, as long as precautions are taken and a careful follow-up during pregnancy occurs, especially in patients who wish to remain fertile. and hemorrhages.$^{3.5}$ It has already been used to reduce trophoblasts of ectopic gestations (tubarian, abdominal and cervical), ${ }^{5.7}$ and some reports used methotrexate for treatment of placenta accreta after pregnancy. ${ }^{3.7}$

We initially decided to use methotrexate, based on reports of cervical gestations in which it was used successfully and hysterectomy avoided, ${ }^{5}$ and in placenta accreta cases in which it was used after pregnancies, ${ }^{3.7}$ with hysterectomy being avoided in one case. ${ }^{3}$ However, after this chemotherapy there was no change in the patient's condition. Although the procedure could have been repeated, we opted for surgery, since reports state that delaying hysterectomy may worsen maternal prognosis, ${ }^{1.2 .6}$ and implicating surgery becomes technically more complex as pregnancy progresses, and could cause more complications.

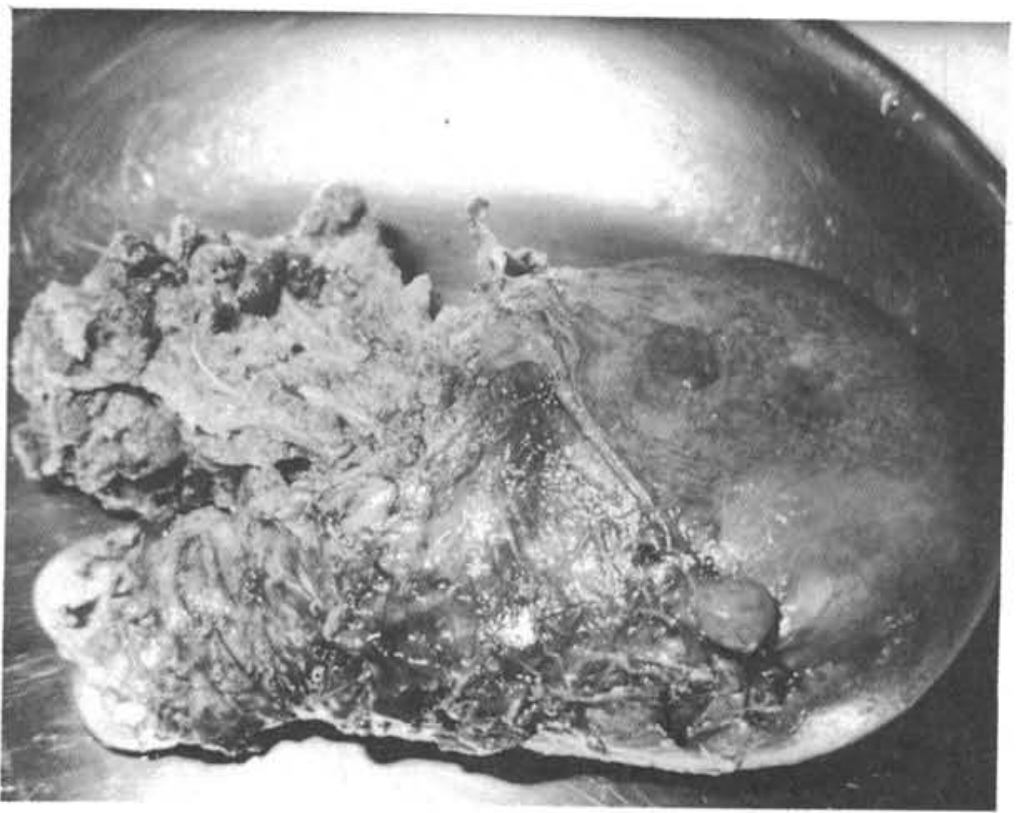

Figure 3 - Uterus with rupture and placenta. 


\section{RESUMO}

Apresentamos um caso de placenta percreta diagnosticado na $14^{\text {a }}$ semana de gestação por ecografia e dopplerfluxometria, diante do qual foi tentado, inicialmente, um tratamento com Methotrexate, que foi, após uma semana, considerado ineficaz. Foi entāo, realizada uma histerectomia total abdominal com diagnóstico intra-operatório de rotura uterina sub-clinica e aderência placentária ao teto vesical. A seguir apresentamos uma discussão baseada em dados de literatura sobre incidência, etiologia, diagnóstico, tratamento e complicações da patologia.

However, surgery is the option that leads to the lowest maternal morbidity, and should not be postponed if conservative treatment is ineffective or in case of bleeding, shock or any other complication.

\section{REFERENCES}

1. Breen JL, Neubecker R, Gregori CA, Franklio JE. Placenta accreta, increta and percreta, a survey of 40 cases. Obstet Gynecol 1977;49:43-6.
2. Cox SM, Carpenter RJ, Cotton DB. Placenta percreta: Ultrasound diagnosis and conservative surgical management. Obstet Gynecol 1988;71:454-6.

3. Legro RS, Price FV, Hill LM, Caritis SN. Nonsurgical management of placenta percreta: A case report. Obstet Gynecol 1994;83:847-9.

4. Read JA, Cotton DB, Miller FC. Placenta accreta: Changing clinical aspects and outcome. Obstet Gynecol 1980;56:31-4.

5. Kaplan BR, Brandt T, Javaheri G, Scommegna A. Successful treatment of a live cervical pregnancy with mehotexate and folinic acid - a case report. Repro Med 1989: 853-6.

6. Vettraino I, Graham C, Shyken J, Khodadoust K, Kivikoski A. Placenta percreta: A case of maternal death. Maternal Fetal Medic 1993;2:276-8.

7. Jaffe R, DuBeshter B, Sherer DM, Thompson EA, Woods JR. Failure of metrotexate treatment for term placenta percreta. Am J Obstet Gynecol 1994;August:558-9. 